
ТУБЕРКУЛЕЗА ОРГАНОВ ДЫХАНИЯ

\author{
ЛещукT. Ю.(tleshhuk@yandex.by),ГельбергИ.C.(ftizagrsmu@gmail.com), \\ ВольфC. Б. (volf_sb@mail.ru) \\ УО «Гродненский государственный медицинский университет», Гродно, Беларусь
}

\begin{abstract}
Введение. Своевременное выявление туберкулезной инфекичи во всем мире в настоящее время остается актуальной проблемой.

Цель исследования: оиенить эффективность профилактических ичифровых рентгенофлюорографических обследований в своевременной диагностике туберкулеза органов дыхания (ТОД) в настоящее время.

Материал и методы. Проведен анализ 247 медицинских карт стационарного паџиента по выявлению ТОД у поступивших на стационарное лечение. Все обследованные паџиенты разделены по методу выявления ТОД на две группы: методом изифровых профилактических рентгенологических обследований и по обращению.

Результаты. При профилактических циифровых рентгенофлюорографических обследованиях выявлено 188 $(76,1 \%)$ случаев заболевания, при обращении - 59 (23,9\%).

Bыводы. В настоящее время ведущим методом своевременного выявления туберкулеза органов дыхания остается рентгенологический метод.

Ключевые слова: туберкулез органов дыхания, рентгенодиагностика, бактериоскопия.
\end{abstract}

В настоящее время борьба с туберкулезной инфекцией остается актуальной проблемой [1]. По данным Всемирной организации здравоохранения, в 2015 г. по всему миру заболели 9 млн и умерли 1,5 млн человек. Более 95\% случаев смерти от туберкулеза происходит в странах с низким и средним уровнем дохода. В Европейском регионе ежегодно регистрируется 78 тысяч случаев заболевания туберкулезом, устойчивым к противотуберкулезным лекарственным препаратам [2]. В 2015 г. зарегистрировано около 323000 (36,0 на 100 тыс. населения) новых случаев туберкулеза и рецидивов, 32000 (3,5 на 100 тыс.) случаев смерти от туберкулеза.

В Республике Беларусь проводится постоянная работа по улучшению эпидемиологической ситуации по туберкулезу в рамках реализации Государственной программы «Здоровье народа и демографическая безопасность Республики Беларусь на 2016-2020 гг.» подпрограммы «Туберкулез», Программы международной технической помощи ПРООН и ныне действующей стратегии ВО3 «Положить конец эпидемии туберкулеза» [3]. В 2016 г. в нашей республике заболеваемость туберкулезом и его рецидив составили 34,1 на 100 тыс. населения. По сравнению с 2005 г. заболеваемость $(55,0$ на 100 тысяч населения) снизилась в 1,6 раза, уровень смертности от туберкулеза - в 3,5 раза (с 12,1 до 3,4 на 100 тыс. населении) $[4,5]$.

В Республике Беларусь сохранилась и действует стройная система профилактических рентгенофлюорографических исследований. Профилактические исследования выполняются дифференцированно у подлежащего контингента [6]. На этапах амбулаторно-поликлинической помощи профилактические исследования выполняются на цифровых аппаратах отечественного производителя. Переход на цифровое изображение имеет ряд преимуществ перед аналоговыми аппаратами $[7,8,9]$. Основные преимущества - высокое качество изображения, низкая дозовая нагрузка и экономичность $[8,9]$. С 40-х годов XX века профилактические флюорографические исследования были ведущим методом в раннем выявлении туберкулеза органов дыхания (ТОД) [10]. В современный период ведутся дискуссии о целесообразности широкого использования скрининговых флюорографических обследований с целью выявления туберкулеза. Многие авторы выступают в защиту использования флюорографических обследований $[11,12,13]$. В то же время во многих странах массовые профилактические рентгенофлюорографические обследования признаются необязательными и практически не используется. По рекомендациям ВО3, у пациентов с наличием симптомов, подозрительных на туберкулез, для подтверждения бактериовыделения микобактерии туберкулеза (МБТ) проводят бактериоскопию окрашенных мазков без предварительного рентгенологического обследования. Ранняя и своевременная диагностика туберкулеза органов дыхания является достаточно актуальной проблемой.

Цель исследования - оценка эффективности профилактических цифровых рентгенофлюорографических обследований в своевременной диагностике туберкулеза органов дыхания в настоящее время.

\section{Материал и методы}

Ретроспективно изучены 247 медицинских карт стационарных пациентов, проходящих лечение по поводу ТОД в Гродненском областном клиническом центре «Фтизиатрия». Среди них $196(79,4 \%)$ мужчин и $51(20,6 \%)$ женщина. Медиана возраста мужчин составила $47,0 \pm 2$ года, женщин - 38,0 7,3 года ( $\mathrm{W}=4378,5, \mathrm{p}=0,1579$ по критерию Манна-Уитни).

Все обследованные пациенты в зависимости от метода выявления ТОД были разделены на две группы. Первую составили пациенты, у которых ТОД заподозрен при проведении профилактического рентгенофлюорографического об- 
следования $(\mathrm{n}=188)$ и в последующем подтвержден. Во вторую вошли пациенты, у которых ТОД выявлен при обращении в лечебное учреждение с жалобами бронхопульмологического и интоксикационного характера $(n=59)$ и также в последующем подтвержден.

Статистическая обработка данных проводилась с помощью специализированного для статистического анализа языка программирования «R» версии 3.4.0. В качестве интегрированной среды разработки использовалась среда «RStudio» версии 1.0.143. Сравнение долей проводилось с помощью Z-критерия сравнения долей. Различия считались статистически значимыми при $\mathrm{p} \leq 0,05$.

\section{Результаты и обсуждение}

Среди обследованных пациентов встречались разные клинические формы туберкулеза органов дыхания. Их структура представлена в таблице 1.

Tаблица 1. - Структура заболеваемости ТОД

\begin{tabular}{|l|c|c|}
\hline $\begin{array}{c}\text { Клинические формы } \\
\text { туберкулеза органов дыхания }\end{array}$ & $\begin{array}{c}\text { Абсолютное } \\
\text { число } \\
\text { обследованных }\end{array}$ & Процент \\
\hline Очаговый & 56 & 22,7 \\
\hline Инфильтративный & 164 & 66,4 \\
\hline Туберкулема & 17 & 6,9 \\
\hline Диссеминированный & 8 & 3,2 \\
\hline Казеозная пневмония & 2 & 0,8 \\
\hline \multicolumn{1}{|c|}{ Всего } & 247 & 100 \\
\hline
\end{tabular}

Как видно из таблицы 1, в структуре заболеваемости ТОД преобладает инфильтративная форма заболевания $(164-66,4 \%)$, очаговый туберкулез выявлен у 56 (22,7\%) пациентов, туберкулема - у 17 (6,9\%). Реже встречался диссеминированный туберкулез - 8 (3,2\%) пациентов, а в единичных случаях казеозная пневмония $2(0,8 \%)$.

В результате анализа результативности профилактических рентгенофлюорографических обследований установлено, что данным методом выявлены 188 пациентов $(76,1 \%$ случаев из общего числа), из них 147 (78,2\%) мужчин и $41(21,8 \%)$ женщина. Полученные нами данные по выявлению туберкулеза органов дыхания вышеуказанным методом, схожи с показателями ТОД по Гродненской области. Так, в 2015 г. при проведении профилактических рентгенофлюорографических обследований установлено 78,4\% случаев (от общего числа выявленных пациентов с ТОД), в 2016 г. - 80,1\%, в 2017 г. $-75,5 \%$ [14]. В то же время у $59(23,9 \%)$ пациентов ТОД был выявлен, когда они обратились в лечебные учреждения с жалобами интоксикационного и бронхолегочного характера. Среди них 49 (83,1\%) мужчин и 10 (16,9\%) женщин. Клинические формы ТОД у пациентов с разными методами выявления представлены в таблице 2 .
Таблица 2. - Клинические формы ТОД у пациентов с разными методами выявления заболевания

\begin{tabular}{|l|c|c|}
\hline $\begin{array}{c}\text { Клинические } \\
\text { формы } \\
\text { туберкулеза органов } \\
\text { дыхания }\end{array}$ & $\begin{array}{c}\text { Группа 1 } \\
\text { Пациенты, } \\
\text { выявленные при } \\
\text { профилактическом } \\
\text { рентгенофлюоро- } \\
\text { графическом } \\
\text { обследовании }\end{array}$ & $\begin{array}{c}\text { Группа } 2 \\
\text { Пациенты, } \\
\text { выявленные } \\
\text { при обращении } \\
\text { за медицинской } \\
\text { помощью }\end{array}$ \\
\cline { 2 - 3 } & абс. число (\%) & абс. число (\%) \\
\hline Очаговый & $48(25,5 \%)$ & $8(13,6 \%)$ \\
\hline Инфильтративный & $122(65,0 \%)$ & $42(71,2 \%)$ \\
\hline Туберкулема & $17(9,0 \% 0)$ & $7(11,8 \%)$ \\
\hline Диссеминированный & $1(0,5 \%)$ & $2(3,4 \%)$ \\
\hline Казеозная пневмония & - & $59(100 \%)$ \\
\hline Всего & $188(100 \%)$ & - \\
\hline
\end{tabular}

Как видно из таблицы 2, в структуре заболеваемости ТОД в обеих группах преобладает инфильтративная форма 65,0 и $71,2 \%$, соответственно. Напротив, очаговый туберкулез более чем в два раза чаще выявляется при профилактическом обследовании, чем при обращении за медицинской помощью (25,5 и $13,6 \%$, соответственно). Схожая ситуация наблюдается и при выявлении пациентов с туберкулемами. Это не удивительно, поскольку при этих формах редко отмечаются клинические проявления заболевания, которые заставляют обратиться к врачу. Иная картина выявлена при диссеминированном туберкулезе и казеозной пневмонии. Пациенты с этими формами заболевания выявлялись в основном при обращении.

Туберкулез является инфекционным заболеванием. Источником инфекции в абсолютном большинстве случаев является бактериовыделитель, т. е. человек у которого в мокроте обнаружены МБТ. Изучена частота бактериовыделения у обследованных пациентов (рис. 1).

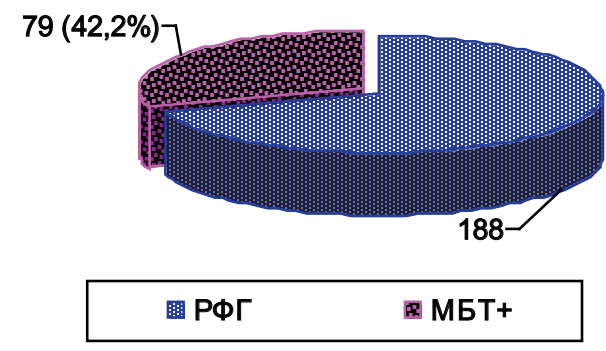

Рисунок 1. - Частота бактериовыделения у пациентов с ТОД, выявленных при профилактических рентгенофлюорографических обследованиях

Как видно на рисунке 1, среди 188 пациентов первой группы, где ТОД выявлен при профилактических рентгенофлюорографических обследованиях, у $79(42,02 \%)$ в процессе дальнейшего обследования были обнаружены МБТ в мокро- 
те. Указанные пациенты не имели клинических проявлений, не обращались за медицинской помощью и были выявлены при профилактических осмотрах. Число бактериовыделителей во второй группе несколько превышало данный показатель в первой группе (рис. 2).

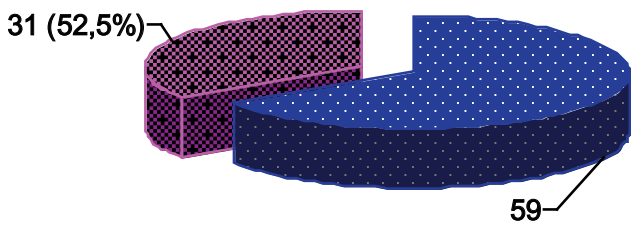

- при обращения в МБТ+

Рисунок 2. - Частота бактериовыделения у пациентов с ТОД, выявленных при обращении

Как видно на рисунке 2, среди 59 пациентов с ТОД выявленных при обращении, у 31 (52,5\%) установлено бактериовыделение.

Своевременное выявление туберкулеза легких имеет большое значение в предотвращении трансмиссии инфекции среди здоровых людей, а также в раннем назначении противотуберкулезного лечения. Проведен сравнительный анализ методов выявления ограниченных (поражение до двух сегментов легких) и распространенных (поражение более двух сегментов легких) форм туберкулеза легких у 247 пациентов (табл. 3).

Таблица 3. - Структура распространенности поражения легких у пациентов с ТОД, выявленных разными методами

\begin{tabular}{|c|c|c|c|c|}
\hline \multirow{2}{*}{$\begin{array}{c}\text { Формы } \\
\text { туберкулеза }\end{array}$} & Всего & $\begin{array}{c}\text { Число обследованных пациентов } \\
\text { Пациенты, выяленные } \\
\text { притофилактическом } \\
\text { рентолюоро- } \\
\text { графическом } \\
\text { обследовании }\end{array}$ & $\begin{array}{c}\text { Группа 2 } \\
\text { Пациенты, } \\
\text { выяленные } \\
\text { при } \\
\text { обращении }\end{array}$ & $\mathrm{p}$ \\
\hline Ограниченные & $136(55,6 \%)$ & $111(59,1 \%)$ & $25(42,4 \%)$ & $\mathrm{p}<0,05$ \\
\hline Распространенные & $111(44,9 \%)$ & $77(40,9 \%)$ & $34(57,6 \%)$ & $\mathrm{p}<0,05$ \\
\hline Всего & $247(100 \%)$ & $188(100 \%)$ & $59(100 \%)$ & - \\
\hline
\end{tabular}

Примечание: $p$ - сравнение показателей между ограниченныли и распространенными формами
Как видно из таблицы 3, сравнительный анализ показал, что в структуре распространенности специфического воспаления в легких преобладают ограниченные формы $(136-55,6 \%)$, которые выявлялись в 1,2 раза чаще, чем распространенные формы $(111-44,9 \%)$. При этом они значимо чаще выявлялись при профилактическом рентгенофлюорографическом обследовании, чем при обращении (59,1\% против 42,4\%, $\mathrm{p}<0,05)$. Распространенные формы напротив более часто выявлялись при обращении $(57,6 \%)$, чем при рентгенофлюорографических обследованиях $(40,9 \%), \mathrm{p}<0,05$.

Полученные результаты свидетельствуют, что один из используемых в Беларуси методов выявления ТОД, а именно профилактическое рентгенофлюорографическое обследование с широким охватом населения, сохраняет актуальность и в наши дни. Тем более что современные цифровые методы рентгенофлюорографического обследования значительно экономичнее аналоговых (пленочных) и практически безвредны. Если при аналоговой флюорографии старым методом пациент получал дозовую нагрузку $0,5 \mathrm{~m}^{3}$ в, то в настоящее время при цифровых обследованиях - 0,015 м³3, т. е. дозовая нагрузка на организм пациента снижается в 33,3 раза.

\section{Выводы}

1. Ведущим методом своевременного выявления пациентов с ТОД в настоящее время остается метод профилактических цифровых рентгенофлюорографических обследований, который позволил выявить ТОД в 76,1\% случаев, что 3 раза выше, чем при обращении пациентов с жалобами $(23,9 \%)$.

2. Среди 188 пациентов, выявленных при профилактических рентгенофлюорографических обследованиях, у 79 (42,2\%) в последующем обнаружено бактериовыделение.

3. Ограниченные формы ТОД значимо чаще выявляются при проведении рентгенофлюорографических обследований в сравнении с выявлением по обращаемости.

4. Внедрение современной низкодозовой цифровой рентгенофлюорографии позволяет своевременно, эффективно и качественно проводить выявление ТОД.

\section{Литература}

1. Глобальные отчеты Всемирной организации здравоохранения по туберкулезу: формирование и интерпретация / И. А. Васильева [и др.] // Туберкулёз и болезни лёгких. 2017. - Т. 95, № 5. - С. 7-16.

2. World Health Organization. Global tuberculosis report, 2015, WHO [Electronic resource]. - 20 th ed. - Geneva, 2015. - 204 p. - Mode of access: http://apps.who.int/iris/bits tream/10665/191102/1/9789241565059 eng.pdf. - Date of access: 10.11.2017.
3. Совет Министров Республики Беларусь. Государственная программа «Туберкулез» на 2010-2014 годы [Электронный ресурс] : утв. постановлением, 8 января 2010, № 11 // Законодательство Республики Беларусь : база нормативных правовых актов. - Режим доступа: http:// pravo.newsby.org/ belarus/postanovsm3/sovm513.htm. - Дата доступа: 10.11.2017.

4. Клиническое руководство по лечению туберкулеза и его лекарственно-устойчивых форм / [Е. М. Скрягина [и др.]. - Минск, 2012. -84 с. 
5. Гуревич, Г. Л. Диагностика и дифференциальная диагностика туберкулеза легких на различных уровнях оказания медицинской помощи в Республике Беларусь / Г. Л. Гуревич, Е. М. Скрягина, О. М. Залуцкая // Туберкулез и болезни легких. - 2014. - Т. 91, № 1. - С. 14-19.

6. Клиническое руководство по организации и проведению противотуберкулезных мероприятий в амбулаторно-поликлинических организациях здравоохранения / Г. Л. Гуревич, Л. А. Жилевич, А. П. Астровко, В. З. Русович ; ГУ «РНПЦ пульмонологии и фтизиатрии». - Минск : Белсэнс, 2013. - $100 \mathrm{c}$.

7. Опыт использования в условиях поликлиники малодозной цифровой рентгенографической установки МЦРУ "Сибирь-Н" / Е. А. Бабичев [и др.] // Вестник рентгенологии и радиологии. - 1998. - № 4. - С. 28-32.

8. Горбунов, Н. А. Сравнительная оценка информативности интерактивной цифровой рентгенографии и традиционной крупнокадровой флюорографии при скрининговом исследовании органов грудной клетки / Н. А. Горбунов, В. П. Шурыгин // Вестник рентгенологии и радиологии. 2000. - № 4. - С. 20-23.

9. Михайлов, А. Н. Роль рентгенологии в раннем распознавании туберкулеза легких / А. Н. Михайлов // Новости лучевой диагностики. - 1999. - № 3. - С. 7-8.

10. Фтизиатрия : национальное руководство / гл. ред. М. И. Перельман. - Москва : ГЭОТАР-Медиа, 2007. - 506 с.

11. Возможности повышения качества проведения профилактических осмотров населения на туберкулёз / Е. М. Богородская [и др.] // Менеджмент качества в сфере здравоохранения и социального развития. - 2012. - № 1 (11). - С. $34-40$.

12. Борисов, С. Е. Выявление и диагностика туберкулеза / С. Е. Борисов, В. Ю. Мишин, В. А. Аксенова // Проблемы туберкулеза и болезней легких. - 2007. - Т. 84, № 11. - С. 47-63.

13. Туберкулёз в городе Москве (2011) : аналитический обзор / В. И. Литвинов [и др.] ; Московский городской научно-практический центр борьбы с туберкулезом. Москва : МНПЦБТ, 2012. - 249 с.

14. Министерство здравоохранения Республики Беларусь. Об утверждении форм первичной медицинской документации по туберкулезу [Электронный ресурс] : приказ Министерства здравоохранения Республики Беларусь, 9 ноября 2006, № 759 // Бизнес-Инфо : аналитическая правовая система. - Минск, 2018.

\section{References}

1. Vasileva IA, Belilovskij EM, Borisov SE, Sterlikov SA. Globalnye otchety Vsemirnoj organizacii zdravoohranenija po tuberkulezu: formirovanie i interpretacija. Tuberkuljoz i bolezni ljogkih [Tuberculosis and Lung Diseases]. 2017;95(50):7-16. (Russian).

2. World Health Organization. Global tuberculosis report, 2015, WHO [Internet]. 20th ed. Geneva; 2015. 204 p. Available from: http://apps.who.int/iris/ bitstre am/10665/191102/1/9789241565059_eng.pdf. (accessed 10.11.2017).
3. Council of Ministers of the Republic of Belarus. Gosudarstvennaja programma «Tuberkulez» na 2010-2014 gody [Internet]: utverzhdeno postanovleniem, 8 janvarja 2010, № 11. Zakonodatelstvo Respubliki Belarus: baza normativnyh pravovyh aktov. Available from: http://pravo.newsby.org/ belarus /postanovsm3/sovm513.htm. (accessed 10.11.2017). (Russian).

4. Skrjagina EM, Gurevich GL, Astrovko AP, Zaluckaja OM. Rukovodstvo po leheniu tuberkuleza I ego lekarstveno-ustojhevux form. Минск; 2012.84 p. (Russian).

5. Gurevich GL, Skrjagina EM, Zaluckaja OM. Diagnostika i differencialnaja diagnostika tuberkuleza legkih na razlichnyh urovnjah okazanija medicinskoj pomoshhi $\mathrm{v}$ Respublike Belarus [The diagnosis and differential diagnosis of pulmonary tuberculosis at different levels of medical care in the Republic of Belarus]. Tuberkulez $i$ bolezni legkih [Tuberculosis and Lung Diseases]. 2014;91(1):14-19. (Russian).

6. Gurevich GL, Zhilevich LA, Astrovko AP, Rusovich VZ. Klinicheskoe rukovodstvo po organizacii i provedeniju protivotuberkuleznyh meroprijatij $\mathrm{v}$ ambulatorno-poliklinicheskih organizacijah zdravoohranenija. Minsk: Belsjens; 2013. 100 p. (Russian).

7. Babichev EA, Baru SE, Porosev VV, Ukraintsev IG, Khabakhpashev AG, Shekhtman LI, Iurchenko IB. Opyt ispolzovanija $\mathrm{v}$ uslovijah polikliniki malodoznoj cifrovoj rentgenograficheskoj ustanovki MCRU "Sibir-N" [Experience in using at a polyclinic the SIBERIA LOW-DOSE DIGITAL X-RAY UNIT]. Vestnik Rentgenologii i Radiologii [Journal of Roentgenology and Radiology]. 1998;4:28-32. (Russian).

8. Gorbunov NA, Shurygin VP. Sravnitelnaja ocenka informativnosti interaktivnoj cifrovoj rentgenografii $i$ tradicionnoj krupnokadrovoj fljuorografii pri skriningovom issledovanii organov grudnoj kletki. Vestnik Rentgenologii $i$ Radiologii [Journal of Roentgenology and Radiology]. 2000;4:20-23. (Russian).

9. Mihajlov AN. Rol rentgenologii v rannem raspoznavanii tuberkuleza legkih [Early radiological diagnostics of lung tuberculosis]. Novosti luchevoj diagnostiki [News of Beam Diagnostics Belarus]. 1999;3:7-8. (Russian).

10. Perelman MI, editor. Ftiziatrija: nacionalnoe rukovodstvo. Moskva: GJeOTAR-Media; 2007. 506 p. (Russian).

11. Bogorodskaja EM, Smerdin SV, Nechaeva OB, Veretenceva NA. Vozmozhnosti povyshenija kachestva provedenija profilakticheskih osmotrov naselenija na tuberkuljoz. Menedzhment kachestva $v$ sfere zdravoohranenija $i$ socianogo razvitija. 2012;1(11):34-40. (Russian).

Borisov SE, Mishin VJu, Aksenova VA. Vyjavlenie i diagnostika tuberkuleza. Problemy tuberkuleza i boleznej legkih. 2007;84(11):47-63. (Russian).

13. Litvinov VI, Selcovskij PP, Rybka LN, Kochetkova EJa. Tuberkuljoz v gorode Moskve (2011): analiticheskij obzor. Moskva: Moskovskij gorodskoj nauchno-prakticheskij centr borby s tuberkulezom; 2012. 249 p. (Russian).

14. Ministry of Health of the Republic of Belarus. Ob utverzhdenii form pervichnoj medicinskoj dokumentacii po tuberkulezu [Internet]: prikaz, 9 nojabrja 2006, № 759. Biznes-Info: analiticheskaja pravovaja sistema. Minsk; 2018. (Russian). 


\title{
MODERN APPROACHES IN THE EARLY DETECTION AND DIAGNOSIS OF TUBERCULOSIS OF THE RESPIRATORY SYSTEM
}

\author{
Leshchuk T. Yu., Gelberg I. S., Volf S. B.
}

Educational Institution «Grodno State Medical University» Grodno, Belarus

Background: Timely detection of tuberculosis infection worldwide, at present, remains an urgent problem.

Objective: to evaluate the effectiveness of preventive digital X-ray fluorography studies in the timely diagnosis of respiratory tuberculosis (RTB) at the present time.

Material and methods: The analysis of 247 medical records of patients admitted to inpatient treatment aimed at the identification of RTB was carried out. All examined patients were divided into two groups according to the method of RTB detection: by the method of digital prophylactic X-ray examinations; by seeking medical advice.

Results: with preventive digital X-ray fluorography studies 188 cases (76.1\%) were detected, in those seeking medical advice - 59 cases (23.9\%).

Conclusions: Currently the X-ray method remains the leading method for timely detection of pulmonary tuberculosis.

Keywords: respiratory tuberculosis, X-ray diagnostics, bacterioscopy.

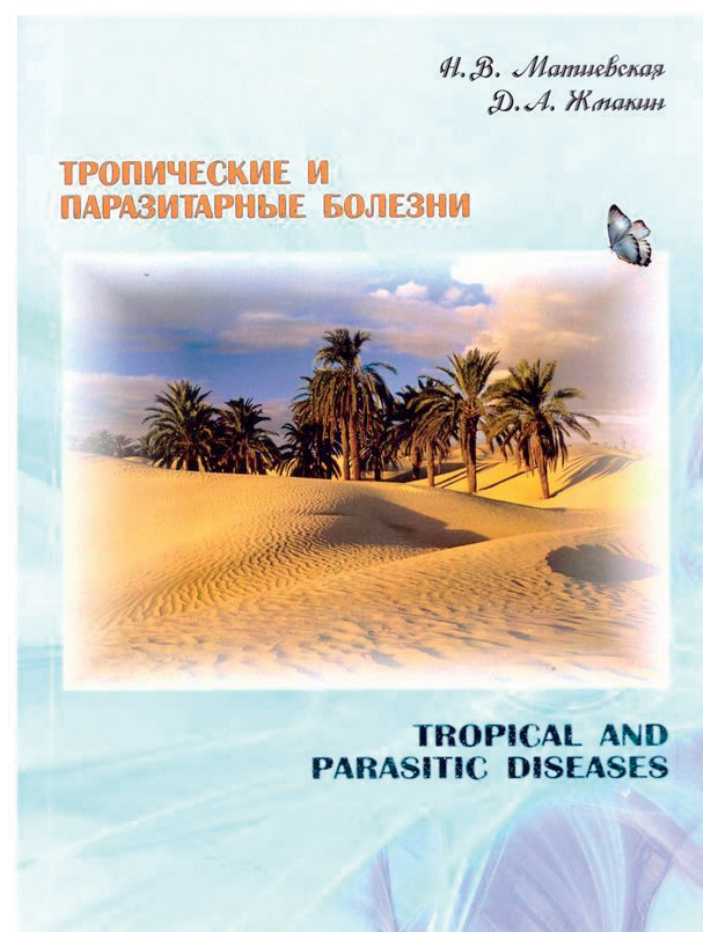

Матиевская, Н. В. Тропические и паразитарные болезни : пособие для студентов факультета иностранных учащихся (английский язык обучения) / Н. В. Матиевская, Д. А. Жмакин ; Министерство здравоохранения Республики Беларусь, Учреждение образования "Гродненский государственный медицинский университет", Кафедра инфекционных болезней = Tropical and parasitic diseases : manual for the Faculty of Foreign Students (English medium) / N. V. Matsiyeuskaya, D. A. Zhmakin. 2-е изд. - Гродно : ГрГМУ, 2018. - 378 с. : рис., табл. Библиогр.: с. 377-378. - ISBN 978-985-558-942-7.

The manual is prepared for the Medical Faculty for International Students according to the requirements of the syllabus and on the basis of modern representations of a medical science. This manual is recommended for students who undergo practical training in infectious clinics. The manual contains data which should be mastered by students according to the curriculum. The information from the manual can be used by physicians in their medical practice. 